\title{
15
}

\section{Self-Consciousness, Social Consciousness and Nature}

The ultimate purpose of the present paper is to reach, and, in closing, to sketch some views as to the relation of Man to Nature. By way of introduction, I must first define the place of my inquiry in the general catalogue of philosophical questions, and must then state the theses that I mean to defend.

There are two great divisions of philosophy-theoretical and practical. The present paper concerns itself with a matter belonging to theoretical philosophy. Within the range of theoretical philosophy, however, one may distinguish between the discussion of the ultimate problems of knowledge and of truth, and the treatment of the more special theoretical problems suggested by our human experience. General Epistemology and general Metaphysics have to do with what can be made out about the deepest nature of our knowledge and the final constitution of the universe. But there are, within the scope of theoretical philosophy, other problems relating to the constitution of our finite world-probiems which are often grouped together as the questions of special metaphysics, or of the Philosophy of Nature-a doctrine to which has also sometimes been given the name Cosmology. The problems of Cosmology are such as the questions: What is the truth behind what we mortals call Nature, or the

A paper read before the Philosophical Club of Brown University, May 23, 1895, and later considerably enlarged and supplemented. [Reprinted from $S G E$, pp. 198-248.] 
physical world? What are finite minds, and how are they related to physical reality? What, if any, is the philosophical interpretation to be given to the doctrine of Evolution?

Now the present paper, as I just said, is an inquiry within the region of theoretical philosophy. Within that region my investigation, however, concerns itself only secondarily with the ultimate problems of general metaphysics. I shall chiefly aim to reach, before I close, light as to a certain problem of philosophical cosmology. Here about us, as we all admit, whatever our ultimate metaphysical views, is the natural world, the world that appears to our senses-a world manifesting some sort of finite, and obviously, as we mortals see it, some sort of highly fragmentary truth. Now man, as we phenomenally know him, appears as a part of nature, a product of nature, a being whose destinies seem to be the sport of purely physical laws. The problem that this paper aims in the end to approach is: What is the meaning of this phenomenal relation of man to nature?

Now, as I need not say, a real answer to this question must lead us past, if not through, the realms of the most ultimate and general sort of metaphysical inquiry. Nor will this paper wholly escape the responsibility of considering to some extent, as we proceed, such ultimate matters. But on the other hand, all philosophical students are used to the fragmentary, and I shall not here attempt completeness. Such general metaphysical views as come in sight in this paper will remain, after all, of rather secondary importance. I shall attempt only to clear some of the way that leads from the study of man as we ordinarily know him towards the regions where general philosophy attempts to grapple with the ultimate issues of life, and with the rational constitution of the universe.

The relation of man to nature-this, then, is our immediate topic. But why, you may ask, if such is the purpose of this paper, have I chosen my actual title? Why does a study of the relations of Selfconsciousness and Social Consciousness seem adapted to throw light on the cosmological problem of the relation of human beings to natural processes? To this preliminary question let us at once address ourselves.

\section{I}

The philosophical examination of man's social consciousness has been left, rather exclusively, in the hands of the students of ethics. 
Even the psychologists, until very recently, have paid a very inadequate attention to the distinctively social aspects of their science. It is far too customary, in consequence, for the ethical philosophers themselves to begin their study of the duties of man with a very abstract view of the nature of the social consciousness, and of its original relations to our self-consciousness. We hear nowadays, for instance, in popular philosophy, a great deal about the supposed primal and natural conflict between Egoism and Altruism. Egoism, so we are told, is the original human tendency-the natural and innate bias of any one of us mortals. And it is so because, as soon as one becomes self-conscious, i. e., aware of one's Ego, one finds one's self, as an animal, instinctively selfish. The practical tendency of the selfpreserving animal organism, translated into the terms of self-consciousness, becomes deliberate Egoism. Hence the moral problem is to make a man altruistic. The philosophical problem of ethics, on the other hand, is to show a man why he ought to be altruistic, i. e., why Egoism, which is naturally prior and apparently self-evident, ought rationally to be subordinated, upon reflection, to its derived and slowly acquired natural opponent, Altruism.

But now, I insist that, as a fact, this far too customary notion of a natural and fatal opposition between self-consciousness, Egoism, and our socially determined and derived Altruism, is also far too falsely abstract a notion. There are evil tendencies in plenty in human nature, and common sense has a very wholesome meaning in mind when it condemns our natural selfishness. But when one defines in philosophical terms our evil tendencies, or undertakes to analyse in an ultimate sense what common sense knows as our selfishness, one does ill if one merely substitutes abstract distinctions for our concrete and passionate life-conflicts. As a fact, the abstract opposition, Ego and Alter, or Egoism and Altruism, ill suggests the meaning of the opposed ethical aims that struggle in us. This whole customary popular and philosophical opposition between a man's self-consciousness, as if it were something primitive and lonely, and his social consciousness, as if that were something acquired, apart from his selfconsciousness, through intercourse with his fellows, is false to human nature. As a fact, a man becomes self-conscious only in the most intimate connection with the growth of his social consciousness. These two forms of consciousness are not separable and opposed regions of a man's life; they are thoroughly interdependent. I am dependent on my fellows, not only physically, but to the very core of 
my conscious self-hood, not only for what, physically speaking, I am, but for what I take myself to be. Take away the Alter from consciousness, and the conscious Ego, so far as in this world we know it, languishes, and languishing dies, whatever may become of the organism in whose fortunes this Ego, while it is known to persist, seems to be involved. Hence, I am not first self-conscious, and then secondarily conscious of my fellow. On the contrary, I am conscious of myself, on the whole, as in relation to some real or ideal fellow, and apart from my consciousness of my fellows I have only secondary and derived states and habits of self-consciousness. I cannot really will to preserve the Ego, then-this derived conscious creature of the habits of my social consciousness; I cannot really will to preserve the Ego, without also willing to preserve and to defend some sort of Alter, and some sort of relation to my fellow who is this Alter, and upon whom my conscious Ego depends for its very life. It is only in abstraction that I can be merely egoistic. In the concrete case I can only be egoistic by being also voluntarily altruistic, however base may be the sort of Altruism that I chance to prefer. I can aim, for instance, to be a political "boss." That appears to be a very egoistic aim. But the political "boss" exists by the suffrages of interested people, and must aim at their conscious, even if illusory, sense of advantage in so far as he wills them to be sincerely interested. I can will to be a flattering demagogue, admired for vain show by a crowd of fools. The end is selfish; but it also involves wishing to be agreeable in the eyes of many people; and even a saint might on occasion wisely include so much of the demagogue's aim in his own vastly different context of voluntary life. The tyrant wills the lives and even the limited good fortune of his subjects, for without powerful and numerous and even devoted subjects he would be no tyrant. The master wills his slave's preservation, even in willing to preserve his own mastery. Even the thief or the defaulter wills that the hoarding of valuable property should be on the average sufficiently advantageous to others to make them willing and careful to provide him with the wherewithal to win his thief's livelihood. Even the murderer, although he directly aims to destroy his fellow, does so, in general, and whenever the act is deliberate and intelligent, for a social end-honor, property, power -all of them ends which involve willing the preservation, and even the prosperity, of many social relations involving others than the murderer himself. There is, then, much bad Altruism in the world, much base wishing of social relations which do involve the preserva- 
tion, and even the relative private advantage of others besides the evil-doer. But bad Altruism is not mere Egoism, nor is it identical with a lower animal's unconsciously naïve selfishness. The mere instincts of the self-preservation of this organism have to be far transcended before one can become consciously egoistic. Vanity, pride, love of social power, the greed of mastery, covetousness, oppression -all these are tendencies that, just in so far as they are conscious and deliberate, involve not only Egoism, i. e., the love of the advantage of this individual, but also some more or less evil form of Altruismthe love of the preservation, and often of a certain limited advantage, of those of one's fellows who form the necessary other term of the social relation which satisfies one's vanity, one's greed, or one's love of power. In brief, speaking ethically, you cannot consciously be merely egoistic. For you, as a man, exist only in human relations. Your aims have to be more or less social, just so far as you clearly define them. The ethical problem is not: Shall I aim to preserve social relations? but: What social relations shall I aim to preserve?

But to return from these illustrations to the general topic: my first point on this occasion is that, just as there is no conscious Egoism without some distinctly social reference, so there is, on the whole, in us men, no self-consciousness apart from some more or less derived form of the social consciousness. I am I in relation to some sort of a non-Ego. And, as a fact, the non-Ego that I am accustomed to deal with when I think and act, is primarily some real or ideal finite fellow-being, in actual or possible social relations with me, and this social non-Ego, real or ideal, is only secondarily to be turned into anything else, as, for example, into a natural object that I regard as a mere dead thing. And I have dwelt upon these facts for the sake of first introducing a matter towards whose final definition the whole of the following argument is to tend, viz., the assertion that what you and I mean by Nature is, as a finite reality, something whose very conception we have actually derived from our social relations with one another; so that, as we shall see, to believe that there really exists a finite reality called Nature, is of necessity, when you rightly analyze the facts, to believe that there is, in the real universe, an extrahuman, but finite conscious life, manifesting its presence to us by means substantially similar to those whereby we have become assured of the presence of the inner life of our human fellows. As it is not true that we are primarily and in unsocial abstraction merely egoistic, just so it is not true that we primarily know merely our own 
inner life as individuals, apart from an essentially social contrast with other minds. While it is true, as all idealistic analysis has affirmed, that the object of knowledge is precisely what it is known as being, it is not true that you and I ever know our own individual inner world of objects, without contrasting these objects with others that we regard as present to some sort of conscious life beyond our own. But primarily we learn to contrast our own inner life with what we regard as the inner life of our fellows in human society. It is by virtue of this very contrast of our own inner life with a finite conscious life beyond our own, viz., that of our human fellows, that we become self-conscious. When later, for reasons that I shall soon define, we learn to oppose to ourselves as finite knowers, a world of relatively independent natural objects, which we conceive as existent apart from any human insight, all the categories in terms of which we can learn to think of these nature-objects are categories derived from our social experience, and modified, but not really transformed, to suit the peculiar behavior of the relatively unsocial beings whose existence our experience seems to indicate to us in nature. Our relations with nature are thus such as involve a more or less social contrast between our life and the life of nature. And upon this principle every philosophy of nature must rest.

\section{II}

I have begun our research, as you see, by some decidedly general and positive assertions. I must next try to show you more precisely and more in detail what these assertions mean, and why I find myself obliged to hold them.

The theses of the present paper, set forth in particular, run as follows:

I. A man is conscious of himself, as this finite being, only in so far as he contrasts himself, in a more or less definitely social way, with what he takes to be the life, and, in fact, the conscious life, of some other finite being-unless, indeed, he modifies his natural self-consciousness by contrasting his own life with the conceived fullness of the life of God. But except by virtue of some such contrast one cannot become self-conscious, and the result is that, as a matter of simple and necessary meaning, if any metaphysical argument is to prove than I am I, viz., this finite being, then at the same time this argument will prove that there is other conscious life besides mine. For other- 
wise my own finite life as this Ego cannot be defined or conceived.

2. The other conscious life that I must contrast with mine, in order to become self-conscious, is primarily, in our human relations, the life of my fellow in the social order. The original, as Hume would say, of the conception of a non-Ego is given to me in my social experiences. The real other being that I, as this finite Ego, can know is, at first, the human being. A man who had no social relations could form no clear conception of the reality of any finite non-Ego, and so could get no clear notion of the reality of the non-Ego now called Nature. Our conception of physical reality as such is secondary to our conception of our social fellow-beings, and is actually derived therefrom.

3. In consequence, any metaphysical proof that what we human beings mean by physical nature exists at all, must also be a proof that behind the phenomena of nature, just in so far as nature has finite reality, there is other conscious life, finite like our own, but unlike human life in so far as it, the nature-life, does not enter into closer relations with us human beings. Yet all that manifests to us the external existence of nature, does so by virtue of a more or less definite appeal to the categories of our social consciousness.

4. But, as a fact, a probable proof, not amounting to philosophical demonstration, but capable of an indefinite degree of extension and illustration, does exist for the existence of a real finite world called the Realm of Nature. Hence, this very proof indicates that there is behind the phenomena of nature a world of finite life in more or less remote, but socially disposed relations to us human beings.

5. This proof of the finite reality of a conscious life behind the phenomena of nature is furnished by the whole mass of facts that in modern times have come to be conceived together as the basis of the doctrine of Evolution. And the doctrine of Evolution must in the end be interpreted in terms of this notion. In other words, the doctrine of Evolution seems to me the beginning of what promises to become a sort of universal Sociology, tending towards a definition of the social relations of the finite beings that together must make up the whole natural world, both human and extra-human.

6. Yet, on the other hand, the view of nature thus indicated ought to be very sharply distinguished, both from most traditional forms of Animism and of Hylozoism, and from the modern doctrine of Mind-Stuff. The view that I have in mind is not Schopenhauer's doctrine of the Will in Nature, nor Schelling's Naturphilosopbie, 
nor von Hartmann's theory of the Unconscious as manifested in physical phenomena. From such theories mine is to be distinguished by its genesis. It tries to avoid all premature dogmatism as to the inner aspect of the life of nature. But it conceives the possibility of a gradual and, as one may hope, a very significant enlargement, through the slow growth of human experience, of our insight into the inner meaning of nature's life, and into the essentially social constitution of the finite world. Meanwhile this conception of the natural order as a vast social organism, of which human society is only a part, is founded upon no merely animistic analogies between the physical phenomena and the phenomena of our organisms, but upon a decidedly deeper analysis of the very nature of our conception of other finite beings besides ourselves. And further, if my conception is true, it quite transforms certain important aspects of our whole notion of the meaning of Evolution. For the process of Evolution, as I now view it, becomes, not the history of the growth of life from the lifeless, but the history of the differentiation of one colony, as it were, of the universal society from the parent social order of the finite world in its wholeness.

Such, in some detail, are my theses. They need, of course, both analysis and defense. I will take them up in their order, dwelling perhaps too long upon the first thesis, upon which all the rest depends.

\section{III}

First, then, as to the thesis that one is conscious of one's Ego only by virtue of the contrast between this Ego and some consciousness which one regards as external to one's finite self.

Speaking in psychological terms, one can say that our finite selfconsciousness is no primitive possession at all, but is the hard-earned outcome of the contact between the being capable of becoming rational and the rationally-disposed world in which he slowly learns to move. A child becomes self-conscious only by degrees. When, as infant, he cries for his food, or even, when more intelligent, shows lively disappointment if his expectations are not met, he is not yet self-conscious. When later, as older child, he struts about, playing soldier, or shyly hides from strangers, or asks endless questions merely to see what you will say, or quarrels with his fellows at play, or shrinks from reproof, or uses his little arts to win praise and caresses, he is self-conscious. These latter conditions are all of them 
such as involve a contrast between his own deeds and meanings and the deeds and meanings that he takes to be those of other conscious beings, whom, just as his conscious fellows, he loves or hates, fears or imitates, regards with social curiosity, or influences by devices adapted to what he thinks to be their states of mind. In brief, then, I should assert here, as a matter of psychology, what I have elsewhere worked out more at length, that a child is taught to be self-conscious just as he is taught everything else, by the social order that brings him up. Could he grow up alone with lifeless nature, there is nothing to indicate that he would become as self-conscious as is now a fairly educated cat.

But in the present paper I am dealing, not with psychology, but with certain aspects of the constitution of our knowledge. Let us consider briefly our self-consciousness, now that it has developed. It is a familiar paradox of idealistic analysis that we can have true knowledge of ideas or other objects of consciousness only in so far as they have first been presented to ourselves in our own inner life. Whatever I know must be really known to me, one says only in so far as it is in me. I know, or can conceivably come to know, my own states, my own presentations, my own thoughts, my own experiences. Things external to me can be known only in so far as they first appear inside my conscious world. When I pretend to know something about a far-off star, that something which I know proves, upon analysis, to be my own state, my experience, or my thoughtnothing else. I cannot transcend consciousness. And consciousness is for me $m y$ consciousness, or, at least, can always come to be regarded as mine. "Das 'Ich denke,'" says Kant, "muss alle meine Vorstellungen begleiten können."

Now all this is, in one sense, quite true. There is an aspect of knowledge which is always dependent upon my presentations, my direct acquaintance with mental contents. Without such direct acquaintance, I have no knowledge. But, on the other hand, if one asks a little more closely about the implications of our inner consciousness, one comes upon another, a strongly contrasted, and a highly momentous aspect of our human knowledge. And this aspect is indicated by the well-known fact that if I can only really know my own inner states in so far as they are inner, still, on the other hand, I can never really define to myself just how much is actually presented at any one moment to my inner life. One can know the far-off star only by virtue of ideas and experiences that get presented in the inner 
life; but, on the other hand, this presentation, merely as such, is not enough. For if anything present in the inner life were, as such, at once and altogether known to me, I should always be able to know just what it is, just how much it is, that now constitutes the whole filling and meaning of my inner life. But alas, I never can find out in all my life, precisely the whole of what it is that gets presented to me in any one moment. Are you now conscious of all that is in your field of vision, e.g., of the head of every person who sits in this audience within this instant's range of your vision? Obviously you are not, or at least are not equally conscious of all the possible objects of your momentary visual attention. You are now clearly aware only of what you are now attending to, and not of all the contents that are present but that you merely might attend to if you chose. But once more, what is precisely the whole of what you are now attending towords, thoughts, sights, faces? It is impossible just now exhaustively to tell yourself, unless-unless you first attend to your own process of attention, capriciously fixate its normal fluctuating attitudes, and so give an artificially prepared account of a deliberately falsified situation. The inner life, as we get it, is conscious, but normally very unequally self-conscious-possesses contents, but cannot precisely define to itself what they are; seeks not to hold the present, but to fly to the next; scorns the immediate, the presented, and looks endlessly for the oncoming, the sought, the wished-for, the absent, so that the inner eye gazes on a flowing stream of events, but beholds rather what they hint at than what they present.

Now it is this other, this curiously contrasted aspect, of our finite knowledge, that constitutes one of the deepest problems of the life of human reason. I can know only what can get presented to me. But, on the other hand, most of what gets presented to me always escapes my knowledge. I know not the merely presented, as such, but only that which in the presented facts I can hold, apperceive, contrast with other contents, and define as to the real meaning of this object which I am to know. But alas, the moment flits. What I now know turns into what I just now knew, even while I reflect upon it. The direct gets lost in the indirect, the instant in the imperfectly known series of states; and my best approach to finite knowledge appears as only a sort of substituting of expectations and of memories for the desired presentations. If, then, on the one hand, I can know only my own ideas, states, thoughts, presentations, our present unhappy result seems to be that, as a fact, owing to the ceaseless flux of con- 
sciousness, I cannot fully know even these. For, once more, I can know only what I can examine with steadily fixated attention; but while I fixate my attention upon the inner object, it changes even while I observe it. Only the presented can be known: this idealistic proposition seems to be mockingly answered by the fairly tragic counter-assertion: Not even the presented is, as such, known.

In view of these paradoxes of our finitude, in view of the fact that only the presented can, as such, be known, while the presented never stays long enough in one moment of consciousness to allow us fully to know what it is, the actual situation of our human knowledge is simply this: What is always most clearly present to our consciously inquiring intelligence is the conceived relation between some content now immediately apprehended but very imperfectly comprehended, and that which, as we hope, believe, or expect, will be or would be apprehended, when we come more fully to know, or if we now more fully knew the meaning of this immediate datum. What I now experience leads me to expect another experience. My conscious knowledge is, then, mainly of this relation of transition from the immediate fact to the expected outcome. Or again, what I now experience leads me to believe that were I otherwise situated, I should apprehend such and such other facts. My knowledge is here again consciously concerned with the relation between my actual and my conceived possible experience. Or, once more, I now have passing through my mind an assertion, a belief, an opinion. And I am thinking just what it is that I mean by this opinion. In this case, my meaning is partly presented to me, partly conceived as a more fully developed meaning, which I should get presented, or shall find presented, upon a further consideration of what I am aiming to do.

Thus, you see, the original paradox of our idealistic analysis gets corrected by this other paradox. To the unknowableness of whatever cannot get presented is now opposed the equal unknowableness of whatever merely gets immediately presented, without being held through a constant inner appeal from what is presented to what in future will be presented, or to what conceivably would be presented, were consciousness otherwise determined. I know only my own states and ideas; but those I know only by virtue of their conceived relation to states and ideas that will be, or that would be, under other conditions, or in other moments, the contents of my experience.

But, from this point of view, the nature of the world of our knowledge gets transformed. Our only approach to that ideal of knowl- 
edge which complete and fixated presentation would involve if we bad it, is afforded us by the imperfectly presented relation between fleeting actual presentations and conceived possible presentations. And therefore you will observe at once that my notion of my own Ego and of its contents depends upon a certain contrast between these contents and a conceived world of actual or possible experience beyond this Ego. For what I come nearest to knowing at any moment is the relation between imperfectly grasped immediate contents and the conceived experience beyond the moment. It is indeed true, as idealism is accustomed to say, that of a Ding-an-sich, out of relation to possible knowledge, I have and can have no sort of knowledge or conception. For, as soon as I try to tell what such a Ding-an-sich is, I turn it into actual or conceived possible experience, and conceive it only as in such experience. But, on the other hand, my whole knowledge of my inner finite Self and of its meaning is dependent upon the contrast between the immediate experiences of this self and a world of abstractly possible or of genuine experiences not presented to any moment of my inner self as such. Thus, all my finite knowledge involves as much mediation as it contains immediacyassures me of fact only by sending me elsewhere for truth; lets me know something, never the whole, of my actual experience, but through its contrast with possible experience; verifies merely by presupposing experiences now unverified; instructs me by suggesting further problems; tells me who I am by indicating whither I am to go to look for my true self; suggests fulfillment of insight, yet all the while sending me out to wander for more insight; arouses the question, What do I mean? at the very moment when I am attempting to answer the question, What is the experienced datum?

Now this realm of contrasts of the light of present experience and of the shadow of possible or of distant other experience, of presentation and of thought; this dwelling in hope rather than in fulfillment, in search for a lost self rather than in enjoyment of a present self; this realm, I say, and this dwelling constitute the inner finite life of every one of us, in so far as he lives rationally at all. My actual inner life is, then, always contrasted with experience other than is now mine; and the problem of my intellectual life, whatever my worldly calling, is this: Where is the rest of my experience? or, What is the content of the other experience with which mine is even now contrasted?

But it is, of course, vain to regard my inner view of myself as con- 
stituted solely by the contrast between my individual presentation and a possible inner experience that I view as merely my own private, but still individually possible experience. My possible experience and the world of other experience than is now mine-these terms, in a wide but an essentially human sense, constantly include not merely the conceived experiences that I alone in my individual capacity am likely ever to have, or to find individually accessible, but also the whole world of experiences that other human beings either have had, or will have, or may have. The upper Nile valley is, in the general and abstract sense, a possible experience of mine; but I individually shall doubtless never come to get that experience. Yet the upper Nile valley is, and has been, a system of actual and of accessibly possible experiences for very many of my fellow-men. When I conceive the upper Nile valley, there are presented to my inner life, images, map-experiences, and the like; and these I know as meaning something to me, in so far as I contrast these relatively immediate data with the conceived contents of the experience of other men who more directly verify what I only conceive as to that region. And, in fact, the whole contents of my individual experience get regarded as one conscious system of remembered and expected contents, in so far as, in conception, I contrast my own private inner life with the experiences which I attribute to my actual or conceived fellows. I often say that my own inner life, as a whole, past and future, actual and accessibly possible, is better known to me, is more immediate, is more accessible to me, than is your inner life. But what do I mean by saying this? Surely both my past and my future are now as truly and literally unpresentable to me as are your inner states. I have now only my memories of my past, as I have only my beliefs as to your inner states. Directly I can now verify neither set of ideas. What I mean by the relative intimacy and accessibility of my own individual past is, then, only the fact that my notion of my past has a "warmth," a definiteness, a sort of inner assurance, which contrasts with the notion that I form of the past of any other man.

You see, whatever way I turn, I am definable to myself only in terms of a contrast with other experience which might, abstractly speaking, be conceived as mine, but which, as a fact, is viewed either as now inaccessible in comparison with my present experience, or else as the actual or possible experience of my fellow, and so as now more remote than even my own relatively warm and quasi-accessible, although actually unpresentable past experience appears to me 
to be. But to define any sphere whatever as the sphere of my own finite life, i. e., to define my life either as the sphere of my momentary finite life, or as the sphere of my whole human individuality, involves in each case a contrast between what is within my defined Ego, in the way of relatively realized, or warm, or accessible contents of experience, and what is beyond my defined Ego, as a sphere of experiences that, abstractly speaking, I regard as possibly mine, while, as a fact, I contrast them with mine, as being really somehow beyond me, and relatively inaccessible to me. These other experiences, which are not mine in precisely the degree in which what I call mine is viewed as belonging to me-these other experiences are, primarily, the actual experiences of other men. $M y$ opinion means, in general, my opinion as contrasted with opinions which I attribute to other men. My private experience means, primarily, whatever nobody else but myself has experienced, and is therefore defined by contrast with the conception of what everybody else has experienced. In brief, take away the concept of that world of abstractly possible other experience, which might be mine, or which would be mine, if I were you, or Cæsar, or any one else, or which would now be mine if I were once more my past self-take all this other experience out of my conception, and forthwith I lose all means of becoming conscious of my experience as mine, or of knowing what I mean either by my whole individuality, or by my present Ego.

\section{IV}

So far, then, for our first thesis. To myself, I am I, not merely in so far as my inner contents get presented to me, but in so far as I contrast my experience present, or the sum total of my conceived individual experience, with an experience which is, in some sense, not mine, but which is conceived as other than mine.

But now what warrant have I, philosophically speaking, for assuming that there is any other experience than mine at all-any experience past or future, remote or warm, like my present experience, or unlike it? Is this merely a practically warranted assertion of common-sense, or has it a deeper philosophical basis?

The general answer to this question is simply that I know the presented experience as such, and in so far as, in passing it is imperfectly grasped at all, only by virtue of its contrast to the conceived other experience. Without knowledge that the other experience is, there 
can be then no meaning in saying that the presented experience itself exists. That the present is, he alone can say who regards the past and future as real. That I as this individual am, I can say only if I contrast myself with some conceived other experience. The judgment: "There is experience," can have meaning only if one defines some experience that is to be thus real. But the only way to define any finite experience is by its contrast with other experience. The total object of true knowledge is therefore never the immediate experience of my own state as such and alone, although there never is any knowledge without some immediate experience as one of its elements. The judgment: "There is experience" means, then, for any finite being, "There is my finite experience, known as somehow contrasted with other experience than what is here presented as mine." Thus, then, the conviction that there is other experience than what is presented to me here, has not only a common-sense value but a philosophical warrant. But if one says: "No, but the contrast is itself something given, and so is not the contrast between my experience and any experience that is really known to be other than mine, but is only a contrast between my presented experience and one that is not presented as other than mine, but that is merely conceived as other than mine"-then to this objection, once more, the answer is, that the very conception of other experience than what is now presented as mine either actually relates to such other experience, or else is a meaningless conception. But if it is to be meaningless, even while it takes itself, as it does, to have a meaning, then this conception that always shadows my presentations, this conception of other experience than mine, is itself an experience that is in fact other than it takes itself to be. For it always takes itself to mean something; although, unless it actually does refer to other experience than mine, it is meaningless. But to say that a conception, or any other presented content of consciousness, is other than it seems, and is, for example, really meaningless when it seems to mean something, this is already to distinguish between my erroneous experience of its nature, and another, a fuller experience of its nature which, if I knew it better, I should have. But thus to distinguish between what my experience really is and what it seems to be, is simply to distinguish between a presented and a not presented aspect of the very experience in question. For what can one say of an experience which is not what it seems to be, and which is yet only a presentation after alla mere matter of the instant in which it happens to live? If an expe- 
rience, viz., here the conception of other experience than mine, presents itself as meaning something beyond the moment when it really means nothing beyond the moment, then this very experience itself is really other than the experience as it is presented, and once more one gets a real contrast between my experience as presented, and related experience which is not presented. The conception of other experience than mine must, therefore, in any case, have relation to a real experience which is other than my presentation.

Thus, then, that there is some experience not individually mine, is an assertion precisely as sure as the assertion that my own experience is. For neither assertion has meaning apart from the other. On the other hand, it is impossible to contrast my experience with any Dingan-sich, existent apart from all experience, because the instant that I tell what I mean by a Ding-an-sich, I have converted it into an experience, actual or possible, and other than mine.

But finally, in this connection, one must still further insist that our now frequently illustrated contrast cannot ultimately be one between my presented experience and an experience other than mine which is barely a possible experience, and not an actual experience at all. A possible experience, not now mine, is a notion that has a very sound meaning in case it has some direct or indirect relation to a real experience not now mine. But bare possibilities, to which no actualities correspond, are indeed meaningless. Are there real facts or aspects of experience not now presented to me, then I can easily define these in terms of logical possibilities. But possibilities need realities to give them meaning. There must then be other experience than mine, not merely as possible experience, but as actual experience. Given such actual experience, there is not only convenience, but rational necessity in the attempt to define its nature in terms of all sorts of conceived possibilities; but unless you have some actual experience upon which to base your possibilities, then the possibilities themselves become mere contradictions. A barely possible experience is, as Mr. Bradley has well said, the same as an impossible experience.

\section{$\mathbf{V}$}

There is, then, an universe of other actual experience than my own finite experience, presented or remembered. Were this central truth not known to me, I should have no means of being conscious of my- 
self as this finite Ego. The general constitution of this world of other experience, in its wholeness, I must here leave to metaphysics. We are now concerned with the finite aspects of the complex of experiences with which, as human beings, we have to do.

Concretely, we get information about the contents of experience not our own, when we communicate socially with our fellows. And the essence of social communication is this: My fellow does something in a certain situation-deals with his environment so or so. $\mathrm{He}$ uses tools, utters words, makes gestures. If these deeds of his are new to me, they do not convey to me his inner experience. These deeds are so far, for me, phenomena in my own experience. I cannot directly view my fellow's experience at all. How, then, is a word, or gesture, or other deed, which as yet conveys no meaning to me, to acquire a meaning, or to become expressive to me of my fellow's inner life as such? The answer is, that, from infancy on, my fellow's expressive acts get a meaning to me as the suggestion of his concrete inner life, just in so far as I am able to imitate these deeds of his by bodily acts of my own, brought to pass under conditions like those in which he, my fellow, acts. For when I definitely repeat a bodily act that expresses any human meaning, the act, as I repeat it, under definite conditions, gets for me an inner meaning which I could never grasp so long as I merely observed such an act from without, as an event in my perceived phenomenal world. But this inner meaning which the act gets when I repeat it, becomes for me the objective meaning of the act as my fellow performs it; and thus the meaning of the imitated act, interpreted for me at the moment of my imitation, gets conceived as the real meaning, the inner experience of my fellow, at the moment when he performs the act which is my model. If you laugh, I know what you mean just in so far as, under similar conditions, I can join with you and laugh heartily also, and can thus, by fully imitating your deed, get a sense of your meaning. But if I see you laughing under circumstances that absolutely forbid me even to conceive myself as imitating your expression of mirth, then I have frankly to say that I do not in the least know what you mean by laughing at just this situation, and so cannot conceive in so far what your inner experience is. If I see you playing cards, or chess, I can only make out what your inner experience is in case I learn the cards, the pieces, the rules, or the moves of the game, and proceed to play it myself. If I want to know what the poets mean when they sing of love, I must myself become a lover. When I have imitated, in 
my measure, the lover's situation, and the lover's sincerely expressed devotion, then I know something of what love meant for the poet. In general, I believe in other human experience than mine in so far as I notice other people's expressive acts, and then gradually interpret them through social conformity. What I cannot interpret by imitation, I cannot definitely realize as another man's experience. Yet as my imitations always remain incomplete, and my interpretations correspondingly indefinite, I have constantly to contrast my fellow's experience, so far as I can realize it, with my fellow's experience so far as it attracts my efforts to interpret it, but also sets a limit to the success of these efforts. And thus I get a notion of a boundless world of human meanings which I can partially, but not wholly, grasp. In the effort, by social conformity, i. e., by imitation of expressive actions, to interpret such inadequately grasped human meanings, a great part of my social life consists. This effort is constantly supplemented by my efforts to convey my own meanings to others; and thus my self-consciousness and my social consciousness, each helped and each limited by the other, since each exists only in contrast with the other, get organized and developed in the endless giving and taking of social communications.

Thus far, then, we have been illustrating our first and second theses. Their application to our notion of Nature remains to be developed.

\section{VI}

So far, then, a reality, external to my finite Ego, means a world of other experience with which my experience is contrasted. This world is concretely defined, in the first place, as the world of other human experiences than my own. What these experiences actually are, I learn only by myself repeating the expressive deeds of my fellows, and by attributing to these deeds, when performed by my fellows, an inner meaning similar to the one which I more directly observe in the deeds when I myself repeat them under conditions similar to those in which my fellows have already performed them. Of course, no such interpretation of any human meaning is infallible; but I am verifiably right in saying that, at every step, this social process does really bring me into relation with experience which, until I performed the deeds of social imitativeness, was not mine. This concrete new experience, which was not mine until I imitated, was then 
before my imitation, at the very least, a possible experience other than mine. The whole social world is full of suggestions of such actually possible experiences. If every real possibility must, logically speaking, have a basis in actuality, I am philosophically warranted in saying that all these suggestions of other human experience which social imitation interprets, and which common-sense trusts, do as a fact stand not only for a barely possible enlargement of my inner Ego, but for real experience which, however fallible my private interpretations of it may be, has an actuality contrasted with, and existent apart from, my finite individuality. The world of my fellows' experiences may not be real just as I, in my narrowness, interpret it. But this world is still, from the philosophical as from the commonsense point of view, a real world, a complex of experiences other than mine, and more or less imperfectly communicated to me. And thus it is that one in general defines the metaphysics of the social consciousness. You observe once more the essential relativity of the individual Ego and the social Alter. Neither conception has any clearness apart from the other.

But now, in our human world of experience, there are, yonder, the phenomena of physical nature. Our next question is, in what sense are we to attribute reality to them?

J. S. Mill's answer to this question is well known, and is, in one aspect, closely and instructively similar to Kant's answer, despite all the differences between the two philosophers as to other matters. The phenomena of nature, e. g., the upper Nile valley, the other side of yonder wall, or of the moon-these one conceives as systems of possible experiences, experiences which, in general, I now have not, but could have under definable conditions. Nature, as such, contains, apart from the bodies of my fellows and of the higher animals, no objects that I conceive as communicating to me any now intelligible inner intents, meanings, plans, or other socially interesting contents. Nature consists of masses of "possibilities of sensation." The problem is, in what sense have these possibilities of experience any inner or self-existent sort of reality? Is nature a Ding-an-sich, whose reality is absolutely inscrutable, but self-possessed? The answer to this last and special question is that such a notion is simply meaningless. I can contrast my experience with other experience, and can regard myself as limited by facts of experience not now presented to me. And such a way of regarding myself is, as we have seen, absolutely essential to even my self-consciousness. But I cannot contrast expe- 
rience with what is no experience at all. Even to say that there now exist certain possibilities of experience which I do not realize, is to raise the issue already several times touched upon in the foregoing. A bare possibility is a mere fiction. It cannot be real. To my true definition of a given experience as merely possible for me, there may correspond an experience which, as it is in itself, is very unlike my private definition of the real possibility. But if I am right in saying, "There is a possibility of experience not now mine," then to such a real possibility some sort of real experience, other than mine, must correspond. The question arises: Is there any such real experience behind those nature-facts which we conceive as our own possible experiences?

But there is another aspect of natural phenomena which perhaps brings us nearer to our goal. The reality of the facts of nature, when we actually confirm their presence, is always viewed as capable of being submitted to social tests. The real nature-phenomenon is not merely conceived as the object of my possible experience, but in general as the object of my fellows' actual or possible experience as well. If the star that I see is a real star, then you, if you are a normal observer can see that star as well as I. This is the common-sense presupposition as to nature. Natural objects are viewed as phenomena that are, in some sense, public property, in so far as many different human observers could make them objects of possible inspection. The presupposition of common-sense is, that many observers could, on occasion, verify the same natural fact; so that the physical world will consist, for common-sense, not merely of possibilities of my individual experience, but of possibilities of common experience on the part of many observers.

Here surely is a well-known, but a paradoxical aspect of our nature-experience. I cannot observe your mind, but, as common-sense supposes, I can observe the same external natural fact that you observe. This presupposition is, in effect, a basis in terms of which we often define the facts of nature. What I alone experience, belongs to my inner life. What you can experience as well as I, is as such a physical fact, and, mind you, this means that, when we deal with nature-phenomena, common-sense supposes us, not merely to have similar inner states, but to refer to actually the same fact. If you as finite being count ten, and I as finite being count ten, we perform similar inner acts, but our objects are so far not the same; for the ten that you count is not the ten that I count. We can in this case be re- 
ferring to the same truth only if there is, as a fact, some of extrahuman reality possessed by the truths of arithmetic, and actually referred to by both of us. But just such extra-human reality common-sense actually attributes to the facts of nature. If ten stones lie on the highway, and you and I count them, common-sense supposes that though your counting of ten is not my counting of ten, though your perception of the stones is not mine, though your inner life is in no fashion, here noteworthy, identical with mine, still the real stones that I count are identically the same as the real stones that you count. Now any natural fact, as common-sense conceives it, could, without losing its identity, be made the common object of as many observers as could come to get the right hints of its nature through their inner experience. All these possible observers, so commonsense holds, would really refer to the same natural fact.

The nature-things, then, are not merely possible experiences for me; they pretend to be possible objects of common experience for many observers.

Now when the nature-facts make such puzzling demands upon us as this, there are only two ways of viewing the situation thus created. One way is to say that in truth, all this common-sense notion of nature is illusory. As a fact, one might insist, it is impossible for two finite observers of nature to have the same external fact actually referred to by both of them at once. What one means is, that, as our social consciousness indicates, human beings have many similar experiences, and can socially convey to one another this similarity of their inner lives. When I rejoice, you may rejoice too; yet our rejoicings are not the same, but only similar. Just so, one might insist, when I point at my star, you may point at your star also. But what happens is that your experience then resembles mine; but has not the same outer object at all. Nature is the sum-total of those facts of our various experiences, concerning which our perceptual experience seems most easily to agree. But this agreement means merely a certain social communicable similarity of our experiences-not unity or sameness of natural object.

This, I say, is one possible hypothesis as to nature. But observe at once: There is one class of nature-objects in case of which just this negative and sceptical hypothesis simply cannot be carried out without destroying the very basis of our social consciousness itself. And this class of seeming outer objects is made up of the very bodies of our human fellows whom we observe, and with whom we socially 
communicate. The social consciousness, upon which, as we have seen, our very self-consciousness itself depends for its definition in finite terms, involves, as an integral part of its unity, the observation of certain natural phenomena definable as the expressive movements, the gestures, words, deeds, of our fellows. Now these phenomena are not merely to be viewed as reducible to the possible similar experiences of the various people who may observe their fellows from without. For these phenomena, on the contrary, have, whoever observes them, their identical and inner aspect; for they indicate the inner life of the social fellow-being who thus expresses himself. Many of you are now observing me. Are all of your various inner experiences of me now actually referring to the same fact, external to you but having for me its presented internal aspect, identically the same whoever it is that regards himself as observing my movements? The answer is here, at once: Yes. If I am I, and am communicating to you through deeds which are represented in you by systems of similar experiences, then, when you experience, in your inner lives, the observable phenomenal aspects of these my deeds, you are all at once meaning, referring to, listening to, the same genuinely real object.

Paradox though it be, the social consciousness insists that the same fellow-man can phenomenally manifest his presence to as many observers as can get some experience of his expressive deeds. All these observers can agree, with due care, as to their accounts of his deeds. These deeds, then, are so far nature-phenomena, like any others. My movements appear to any one of you in space, even as does this desk. So far, one could say, the fact is that the observers have experiences that are similar in one man's case to the experiences of his observing fellow. The observed deeds are merely such similar perceptions in the various observers. The various observers do not see the same real deeds; but they do possess similar perceptions, which they call perceptions of expressive deeds.

But no, this conclusion the social consciousness declines to accept. All your various but similar individual perceptions of my deeds really refer to the same genuine object, precisely in so far as I am I, and in so far as it is my inner experience that is manifested in these deeds. Thus, then, you could say that, if this desk were alone here, you could indeed so far talk sceptically of phenomenal experiences, in various observers, which only seemed to be experiences relating 
to the same object, but which as a fact do not demand the real sameness of their object. But it is no longer so if, in terms of the social consciousness, you consider not the desk, but me as your natureobject. For I am to you not only nature-phenomenon, represented in you by comparable and merely similar perceptual experiences of your various private worlds; but I am, as communicating fellowman, the same outer object for all of you.

Now a similar proposition holds true of any fellow-man. Any man you please has for you his phenomenal aspect. In this aspect he is viewed as object of possible experiences, and the real facts corresponding to this view are, so far, expressible by saying that all of his observant fellows have similar experiences whenever they come into certain definable groups of relations to their own inner worlds. But this man has another existence than the existence of certain images that his fellows form. All of these images refer to him, to the same man, to his manifested inner experience, and so to one reality. And this is what the social consciousness insists. Give up that insistence, in any general form, and you have no social consciousness, no fellow-men with similar experiences, no definable self-consciousness-yes, nothing but an inexpressible immediacy of inner presentations. But hold by that insistence, and what can you say? I answer: You can and must say that to one portion of phenomenal nature, viz., to the observed bodily movements of your fellows, there corresponds an inner life which is the same in essence, however many may be the phenomenal images that observers form of it when they refer to it as a reality.

The first view of nature, viz., that nature consists of a total of possible experiences, similar in various observers, thus fails as to all those nature-objects that present themselves as our expressively moving fellows. Our fellows are real beings, phenomenally observable from without by as many observers as you please, but self-existent as masses of inner experience, contrasted with one another, and with our own experiences.

But now how can you separate the phenomenal fellow, the originally real finite being, the original of your notion of your non-Ego, from the phenomenal nature of which he appears as a part, and with whose existence he appears to be, in all his life, absolutely continuous? For at this point there returns to help us our whole knowledge of human nature as such. A man's phenomenal expressive move- 
ments, objects of possible experience for all observers, stand for, and phenomenally accompany, his inner life. They then are real manifestations of a real interior finite life. But his movements cannot be thus regarded as real unless his limbs, his muscles, his nerves, his brain, his circulatory and nutritive processes, the food that he eats, the desk from which he speaks, the air that he breathes, the room where he speaks, the ancestors from whom he descended-yes, in the end, the whole phenomenal nature-order with which he is phenomenally continuous, unless all these things be also regarded as real in the same general sense, viz., as inner finite experience. In short, you cannot separate your phenomenal fellows from the order of phenomenal nature. The continuity between man and nature, known to us first as the absolute inseparability of the expressive movements of our fellows from the nature-processes in which these movements appear to be imbedded, and of which they are phenomenally a part, has now become, in the light of our whole experience of natural phenomena, an all-embracing continuity, extending to cerebral and to general physiological processes, and to the ancestry and evolution of the human race, so that the highest in expressive human nature is now phenomenally linked by the most intimate ties to the simplest of physical processes. If, then, one's fellow is real, the whole of the phenomenal nature from which his phenomenal presence is continuous must be real in the same general fashion.

But observe, this deduction of the reality of the natural objects implies something very significant as to what nature is. The only possible way to get at the existence of a finite non-Ego is through some form of the social consciousness. What a finite non-Ego is, your fellow teaches you when he communicates to you the fact that he has inner experience, and is the same object, however many observers view him. Now if his continuity with the phenomenal nature of whose processes his observed expressive movements are an inseparable and continuous part, impels you to say that if he is real his whole body, and so, in the end, the whole nature of which that body is an inseparable part and an evolutionary product, is also real, in an inner and finite sense, then the only possible way to interpret this relation is to say: "Nature, by itself, is a system of finite experience which, on occasion, and by means of perfectly continuous evolutionary processes, passes over into, or differentiates from its own organization, the communicative form of socially intelligible experience that you and I call human." 


\section{VII}

The force of this proof is limited, of course, by the fact that it is precisely an argument from continuity. It is capable of endless development and illustration; and I take it to be the only possible proof that nature exists in any way beyond the actual range of our more or less similar human experiences of nature's observable facts. Yet no argument from any continuity of apparent processes has absolute force. It does not follow that every hypothetical conception which you and I now form of this or that natural process, e. g., of the atoms, or of gravitation, corresponds to any distinct form of the inner nature-experience. As a fact, I take it that our scientifically conceived laws of nature are largely phenomenal generalizations from very superficial aspects of the inner life of nature, and that very much indeed of what we now call nature has existence only for human perception and thought, as a matter of the similarities of the experiences of various human observers. But my point is here not a detailed theory, but a general conception of nature. And my general conception is this:-There is a vast system of finite experience, real as our socially communicative fellows are real, and manifesting its existence to us just as they do, viz., through the phenomena which appear to our senses as material movements in space and time. What this inner experience is we know, in case of our human fellows, by social communication. What the rest of the nature-experience is, we can only make out very indirectly. But the continuity proves that the natureexperience passes over, on occasion, by unbroken although vastly complex processes, into the form of human experience. All the facts grouped together as the doctrine of Evolution, make this continuity seem the more elaborate, minute, and significant, the better we know it. In consequence we have no sort of right to speak in any way as if the inner experience behind any fact of nature were of a grade lower than ours, or less conscious, or less rational, or more atomic. Least of all have we a right, as the Mind Stuff theories do, to accept our hypothetical atoms as corresponding to real nature-entities, and then to say that inorganic nature consists of a mass of scattered sensations. Of the reality of organized experience we all know; but scattered sensory states are mere abstractions, just as the atoms of physics are. There is no evidence for the reality of nature-facts which is not defined for us by the very categories of the social consciousness. No evidence, then, can indicate nature's inner reality without also indi- 
cating that this reality is, like that of our own experience, conscious, organic, full of clear contrasts, rational, definite. We ought not to speak of dead nature. We have only a right to speak of uncommunicative nature. Natural objects, if they are real at all, are prima facie simply other finite beings, who are, so to speak, not in our own social set, and who communicate to us, not their minds, but their presence. For, I repeat, a real being can only mean to me other experience than mine; and other experience does not mean deadness, unconsciousness, disorganization, but presence, life, inner light.

But it is customary to say, by way of getting rid of any sort of animism, that we have no right to reason by mere analogy from our inner experience to anything resembling life in inorganic nature. To this I answer that, were the foregoing argument one from analogy, it would be open to the same objections as could be urged against any form of animism. But the whole point of the foregoing analysis has been that you do not first find nature as something real, and occult, and then proceed to argue from analogy that this occult reality is alive. On the contrary, I have first insisted that occult realities, things in themselves, in the abstract sense, are absurd; that the social consciousness gives us the only notion of finite reality that we can have; and that the social consciousness recognizes, as real, beings having conscious experience. After this point was reached, and only then, could we turn, in our argument, to the phenomena of nature to ask if they must be regarded as conforming to just such a concept of finite reality, since, as a fact, this is our only possible concept of what a real being is. Now a phenomenon of nature, on the face of it, is solely something suggested to us by the agreement between the series of experiences present in various men. And no purely physical experience can possibly prove that nature has other reality than this, viz., reality as a series of parallel trains of experience in various people. So far we had not to interpret nature, but only to wonder why nature gets taken to be read at all, apart from these parallel series of experiences. Then it was that there came to our aid the argument from continuity. Certain of the phenomena of nature do stand for real inner experience, viz., the expressive movements of men. It is impossible to separate these latter phenomena, however, from the rest of the natural world, whose phenomenal unity the doctrine of Evolution is now daily making more manifest. Hence-so we reasoned-the rest of phenomenal nature must be regarded as standing for systems of finite experience, whose inner unity has to be defined 
in the way that human experience illustrates. And it is thus, not by analogy, but by the very process whereby nature comes to be defined as real at all, that natural facts get conceived as like other finite experience. Of the relation of this "other experience than ours" in the cosmos, to our human type of experience we can then at once say, that, in the process of evolution, our human experience has become differentiated, by long and continuous processes, from the whole, so that relatively continuous intermediate stages now probably link us to the rest of the cosmical inner life. Of "unconscious" experience in nature we have no right to speak, precisely because consciousness means the very form and fashion of the being of experience itself, as we know it. Of transformations of conscious experience, with a preservation of continuity through the whole process, our own inner life gives us numerous examples.

Meanwhile, let us lay aside, once for all, the petty human Philistinism that talks of the evolution of humanity out of so-called "dead nature," as if it were necessarily a vast progress from "lower" to "higher," or from the meaningless to the world full of meaning. What value human life may get we in a measure know. But we certainly do not know that the nature-experience whose inner sense is not now communicated to us is in the least lower or less full of meaning. Our human evolution is, as it were, simply the differentiation of one nature-dialect, whereby a group of finite beings now communicate together. We have no right to call the other tongues with which nature speaks, barbarous, because, in our evolutionary isolation from the rest of nature, we have forgotten what they mean.

\section{VIII}

A few concluding considerations seem to be still in place in view of the most cogent positive objection that is likely to be urged against the foregoing interpretation of nature. The hypothesis advanced in the foregoing transcends our direct as well as our scientifically mediated experience of nature, just in so far as our view supposes that the nature-phenomena are hints of the existence of a finite experience continuous with ours, but such that its extra-human contents are not communicated to us. And this transcendence of our human experience is indeed a perfectly obvious objection to my notion. Yet the objection is so far only negative. In admitting, as I do, all that such an objection can urge so far as regards the fact that our hypoth- 
esis transcends the limits of present human verification, I still answer that this objection is precisely as cogent against every theory which attributes any sort of genuine inner reality to nature, as it is against our own theory. The objection, in fact, contends only against the attribution of relatively independent reality to nature, just as such attribution, and not against our special view as such. No human verification, made as it is under social conditions, can of itself do more than prove (in the social sense of the word "proof") that various human experiences, existent in different men, have certain actual agreements. To believe that nature has any reality apart from these, our intercommunicable parallel series of human experiences of what we call the nature-phenomena, is, therefore, to transcend the actual data of the social consciousness, so far as they are presented to us mortals. The present objection, then, is equally valid against all cosmological doctrines. The only question really at issue, however, is: What reason forces us to transcend the data of our liberal social consciousness at all? Why are we led to assume a nature outside of the various reports that men give of their parallel trains of describable physical experience? To this question, as I conceive, the only fair answer is the argument from continuity, as it has now been stated. But the argument from continuity is an argument for the existence of finite realities whose ultimate type the social consciousness in general predetermines for our conception, while the nature of their specific relations to our experience is such as to preclude our filling out this general conception of "other experiences than ours" with any particular contents such as we attribute to the communicative minds of our fellows. My argument, then, is not for one concept of the reality of the facts of nature as against contrasting, and equally possible, concepts of the reality of beings other than ourselves. My argument is, that, from the nature of our human consciousness, with its primal contrast of inner Ego and social non-Ego, we can have just one general concept of a finite non-Ego, viz., the concept of "other experience than our own." The only real question, then, is: Shall we attribute this concept, in its most generalized form, to nature, or shall we not? There is no answer to this question except the one derived from our foregoing argument from continuity. That to attribute any reality whatever to nature is to "transcend our own experience," in the human and socially concrete sense of the word "experience," ought to be especially remembered by those who, while glibly attributing to nature a reality which they profess to re- 
gard as utterly inscrutable, are still accustomed to insist that one must never venture to transcend human experience in any fashion.

But it is not this negative argument that I myself regard as the most cogent. I am, as I have just said, more interested in a positive objection which will occur to many of you.

The nature-experience, so our hypothesis supposes, is, in at least a considerable degree, relatively continuous with ours. That is, there is experience in nature which closely resembles human experience; there is other experience which less resembles ours, but which need not be lower; there is conscious experience still more remote from ours; and so on. All this experience hints to us its presence, but only in case of our human fellows communicates its inner meaning to us. But one may now answer: "It is true that the phenomena of our bodies are, physically speaking, continuous with the phenomena of physical nature in general. It is not true, so soon as we leave man, that we get any direct signs of the existence of an inner life, or nature-experience, at all corresponding, in its inner resemblance to, our own, to the physical continuity of its phenomenal processes with our own expressive physical life. The higher animals manifest their inner experience, apparently similar to ours, by expressive activities which resemble ours, but which certainly do not stand in any close physical continuity with ours. Our own organic processes, on the other hand, stand in very close relations of physical continuity with our most intelligent conscious and voluntary deeds. Yet if there is any inner experience connected with those of our organic activities which have no conscious equivalents in our own inner life, it is hard to show any sufficient body of evidence to bring this 'subliminal' experience into any relatively continuous inner relations with our own, despite the numerous, and decidedly interesting, recent efforts which have been made to connect our individual consciousness, by empirical links, with some such 'subliminal' processes." What my theory seems to lack, then, is a definition of any way in which our human consciousness can be in relations of inner continuity with a world of experience which, although thus actually in close continuity with ours, gives signs of its presence only through physical phenomena whose inner meaning, even in case of our own organic processes, quickly escapes any interpretation in terms now intelligible to our socially limited minds. An objector may well urge that this is a positive fault of the theory. Our theory, he may say, need not undertake to tell precisely what the supposed nature-experience contains. But it ought 
to show how physical processes continuous with those of whose inner meaning we are conscious, may involve, as their own inner aspect, types of experience more or less continuously related to our own, and yet now quite inaccessible to us.

As a fact, there is a very obvious way of hypothetically accounting for this presence and inaccessibility of types of experience closely related to ours, whose presence is hinted to us by physical processes such that we now wholly fail to interpret their inner meaning. This supplementary hypothesis is suggested by one of the most interesting and best known principles governing the correlation of mental processes and their phenomenal accompaniments.

Mental processes, in human beings, are correlated to physical processes whose phenomenal or externally observable basis is known to be the functions of nervous systems. Now the best known principle governing the physical fortunes of any nervous system is the principle of Habit. This is the rule that a nervous system tends to repeat its former functions, when once these have become set through series of repeated stimulations. Whatever function has frequently been accomplished under the direction of nervous centers, tends to be the more readily accomplished again. This principle tends, of course, to the production of stability and uniformity of conduct in us all. And the analogy between the results of this special tendency to the formation of nervous Habits, on the one hand, and the existence of the observable processes of Natural Law in general, on the other hand, has often been noted. The phenomenally observable conduct of a being with a nervous system is always, as a fact, and in proportion to the elevation of this being in the scale of life, a very irregular sort of conduct. Yet it tends towards regularity, because of the principle of Habit. Now, however, the regularity of outwardly observable conduct towards which, as towards an asymptote, the conduct of a being with a nervous system tends, is a sort of regularity which physical nature, especially in the inorganic world, continually shows us, only in a highly perfected form, in those extremely regular processes which we define, not, to be sure, as the ideally ultimate laws of the universe, but as the observable routine of phenomenal nature (such routine as is exemplified by the tides, the seasons, etc.). That nature's observable Laws might even be interpreted, from an evolutionary point of view, as nature's gradually acquired Habits, originating in a primal condition of a relatively capricious irregularity, is a conception to which several recent writers, notably Mr. Cope, and, 
with great philosophical ingenuity, Mr. Charles Peirce, have given considerable elaboration. I do not myself accept this notion that the laws of phenomenal nature, where they are genuinely objective laws, and not relatively superficial human generalizations, are the evolutionary product of any such cosmical process of acquiring habits, as Mr. Peirce has so ingeniously supposed in his hypothesis of "Tychism." But I mention the analogy between these regularities of physical phenomena which are called the observable laws of nature, and the gradually acquired regularities of conduct which slowly appear in the lives of beings with nervous systems, in order to introduce another consideration, of equal importance for the definition of the place of conscious experience in the cosmical order.

If it is the rule that our nervous systems tend to form habits, and that habits mean uniformities of phenomenal behavior, it is equally true that our human consciousness tends to grow faint just in proportion as our habits become relatively invariable. Our human and conscious experience is the inner accompaniment of what appears, when viewed from without, as an irregularity of phenomenally observable conduct. Or, in other words, our conscious life is the inner aspect of a physical process of what is called our adjustment to our environment. This adjustment tends to become, in proportion to the perfection of our habits, a matter of predictable routine. But whenever this routine becomes relatively perfect, our consciousness grows fainter, and in the extreme case of an almost entirely invariable physical routine, our consciousness ceases, while the perfected nervous habit remains, for human experience, only as an externally observable phenomenal process of a physical nature. A young man consciously and proudly twirls his moustache. The acquisition of this new mode of conduct constitutes a novel adjustment, and so involves change of routine behavior. This change is accompanied, at first, by a decided sense of personal importance. In time the habit may become set, so that it gets an entirely reflex perfection, and then, as in a well-known reported case, a man struck senseless by a street-accident, and suffering from severe cerebral injury, is seen, as he is carried to the hospital, automatically twirling his moustache, from time to time, in what, from our human point of view, appears as absolute unconsciousness, since we are unable, either then or later, to get into any sort of communication with the conscious experience, if such there be, that forms an inner aspect of this nervous habit. Just so, if one's nervous habits were so well formed, and if one's environment 
were so changeless, that one's whole physical life were a settled series of rhythmically performed activities, recurring with the regularity of breathing, or of the tides, the empirical evidence is that one would have no conscious life of the sort now communicated to us by our social fellows. Consciousness, as we know it in man, and interpret its presence in animals, is an incident of an interrupted adjustment to our environment-an interrupted adjustment which, seen from without, expresses itself in conduct that involves alteration of old babits to meet new conditions. As Romanes well asserted, the signs of mind, in any animal, are best to be defined as just such relative novelties of conduct in the presence of nerw situations. Not routine, then, as such, but irregularity, gives the physically interpretable sign of mind. Habit is always present, in the actions of the obviously conscious being; but, whenever he shows interpretable signs of consciousness, habit is always undergoing alteration.

If one considers these various groups of facts together, one gets, at first, an impression of the place of consciousness in nature which seems quite unfavorable to our hypothesis. Inorganic nature seems to be, as we view it, a realm where physical routine is, at present, obviously much more nearly verifiable, in an exact degree, than is the case with organic nature. In the inorganic world, then, what might be called, by analogy, the habitual process of the cosmos, the observable routine of physical phenomena, seems to be especially fixed, and open in its fixity to our human observation. In the organic world, whether or no the same ultimate natural laws would, if we knew the whole truth, ideally explain the facts, it is obvious that, at present, we see less regularity-less perfected observable habits, so far as our present imperfect experience goes. But, just where we now see least regularity, there we get the only signs of finite minds that we can at present definitely interpret. The ordinary generalization from this whole situation is, that, phenomenal irregularity being characteristic of the physical processes which indicate mind, phenomenal regularity must, by contrast, indicate the presence of the Unconsciouswhatever that may mean.

But now this generalization is open to many objections. The unconscious, as such, is, as a fact, a mere Ding-an-sich, a meaningless abstraction. And, on the other hand, if one leaves out the ultimate presupposition that all of nature's processes, organic and inorganic, are, in some fashion still unknown to us, absolutely and equally uniform-if one, I say, leaves out this ultimate metaphysical presupposi- 
tion, which I intend to examine in another place, and which does not here concern us-and if one confines one's self simply to the phenomenal, and to the empirical differences between organic and inorganic nature, then one must say that the observable or the scientifically computable and verifiable routine of rhythmic repetition in inorganic nature is nowhere concretely known to us as phenomenally invariable. The rhythm of the tides, at any given point, or over the surface of the globe at large, is invariable only if you do not take account of long periods of time. The same holds true of the regularity of the earth's revolution on its axis, and of the change of the seasons. The planetary orbits undergo secular variations, which are, within certain long periods, relatively rhythmic; but if you take a period sufficiently long, these variations are doubtless no longer rhythmic.

As a fact, then, the permanence of the phenomenally obvious "habits" of inorganic nature is only relative. It is true that, if you pass from such observably regular rhythms, whose actual degree of regularity is itself only a varying function of the time taken into account, and if you consider the ultimate and ideal "laws of nature," upon which all such approximate regularities are conceived to be founded, you do, indeed, reach systems of "force functions" conceived as absolutely independent of time. But thus to pass to the ultimate is to substitute a metaphysical conception of rigid causation for the empirically observed uniformities. And this conception which we here omit from consideration, must apply, if true at all, to organic nature quite as much as to inorganic nature. If, however, you cling to the observable "habits" of nature, then the difference between the organic and the inorganic is one only of the length of time required to make a given alteration of habitual sequence in the phenomena manifest. Our solar system is "adapting" itself to an environment of seemingly limitless extent by the well-known dissipation of its energies. This adaptation involves, in varied ways, slow processes of phenomenal change which must, in the end, alter every known phenomenal rhythm of regularly repeated nature-habits. When read backwards, the same tendencies indicate that the present phenomenal order must have been reached by processes whose phenomenal manifestations would have been, in past times, enormously different in their routine from any process now manifest. Even if ultimate laws exist, then, and involve absolutely ideal regularities, which hold for all phenomena, organic and inorganic, it still follows 
that the observable and relatively rhythmic regularities of inorganic nature must be as truly cases of constantly altered "habits," continually adjusted to numerous conditions in the environment, as are the seemingly so irregular expressive acts of our socially expressive fellows. The difference lies in the enormously different times required to make manifest the alterations of phenomenal conduct in question. A business man in a great commercial crisis, or a great general, directing his army during a battle, adjusts his regular routine to the new conditions by changes of conduct that occur within very brief periods. A planet or a solar system alters the routine of its rhythmic processes in ways that it may take millions of years to make manifest. But in both cases the essentials of adjustment are present, viz., variations in the rhythm of characteristic movements occurring in correspondence to changing situations.

If, thus viewed, the difference between the larger phenomenal alterations of inorganic and of organic nature appears mainly as a matter of the time-span involved in each alteration, it remains to consider a little more carefully the relation which we all experience between the inner processes of our conscious experience and those expressive alterations of habit to suit environment which accompany our conscious life.

What appears to our fellows from without as habit altered to meet circumstance, appears from within, in the experience of each of us, as the apperception of relatively new elements of experience by virtue of their relations of similarity and contrast to relatively old or familiar or established masses of inner states. The old, the familiar, the established in consciousness we have always with us whenever we experience. It is the element of our consciousness which corresponds, at any moment, to the established nervous habits just then aroused-to the routine of our lives so far as it is just then repeated. The novel, the puzzling, the intruding element in our consciousness corresponds to the alteration which the environment is at the moment producing in our established physical routine as at that moment represented. We breathe regularly, and are not conscious of the fact. But an alteration in breathing, produced by a novel physical situation, gets represented in consciousness as a shock of surprise. Thus the alteration of our physical routine, at any moment, corresponds to the degree of our conscious experience. The greater the masses and the contrast of the opposing new and old elements, the sharper is our consciousness, and, externally viewed, the more 
marked is our adjustment. If either mass of mental contents tends utterly to overbalance the other, consciousness becomes dim. The effacement of either element means the temporary or final cessation of our whole stream of conscious experience. In sleep one's physical routine is nearly regular, and one's conscious experience vanishes.

Meanwhile, our human experience is subject to another and very important limitation, which we may call The Limitation of our Apperceptive Span. This limitation, so far as we can see, is something purely arbitrary-a mere fact, which we have to accept like the rest of our finite situation. The existence of all such arbitrary limitations is, like the existence in general of any form of finitude, a proper problem for a general metaphysical inquiry. But a merely cosmological study has to be content, in such cases, with accepting the arbitrary fact as such. What is meant, however, by this apperceptive span is the fact that what we call a present moment in our consciousness always has a brief but still by no means an infinitesimal length, within which the "pulse" of change, which that moment apperceives, must fall. Changes of mental content which occur either too swiftly or too slowly to fall within the span of the least or of the greatest time-interval which our human apperception follows escape us altogether, or else, like the slower changes occurring in nature, are only indirectly to be noticed by us. Since the momentary change in the contents of our consciousness corresponds, in a general way, to the externally observable alteration of our physical routine to meet new conditions, one may say, on the whole, that where our established habits are changed too slowly or too quickly, the change is inadequately represented, or is not represented at all, in our individual experience.

Yet a change in our routine which is so slow as to escape our own apperceptive span, is still a fact in the phenomenal world, a fact capable of being recorded and verified. Why may not just such facts be represented by experience which accompanies our own, and which is just as real as ours, but which is characterized by another apperceptive span? This supplementary hypothesis is worthy of special consideration.

No element or character of our human experience, in fact, appears more arbitrary than does the apperceptive span when we submit its phenomena to experimental tests. That the whole of the contents of a finite series of temporal instants should, despite the fact of this temporal succession, form one moment of our consciousness-that, 
for instance, a rhythmic phrase, made up of a number of successive beats, should constitute one presented whole, and stand before our consciousness as such, is in itself a remarkable fact. That, when once this is the case, the length of such a single and presentable rhythmic phrase or other presentable conscious moment should be as limited as it is, is an entirely arbitrary characteristic of our special type of human experience. When once we recognize this aspect of our conscious life, we can conceptually vary indefinitely this temporal span of consciousness, and can so form the notion of other possible experience than ours whose essence, like that of our own, should consist in the contrast between relatively familiar or changeless contents and relatively new contents, but whose apperceptive span should differ from our own in such wise that for such experience a "present moment" might be, when temporally regarded, as much longer or as much shorter than ours as one pleases. A millionth of a second might constitute the span of one such conceivable type of experience. In that case changes of content far too subtle to mean anything to us would be matters of immediate fact to the experience in question. A minute, an hour, a year, a century, a world-cycle might form the apperceptive span of some other possible type of consciousness. In that case inner changes of content which utterly transcend our direct apperception might be matters of presentation to such another type of experience.

Now, however, imagine a system of finite series of experiences, agreeing, in a great measure, in their contents, but differing in some graded fashion, in their apperceptive span. Let each of these series be characterized by the fact that everywhere there were present, in the inner world of each experience, changing groups of contents $A, B, C, D$, the rate of change, however, differing in all the series alike for each group of contents, so that in every one of the series in question the group $A$ changed at some rapid rate $r$, the group $B$ at some slower rate $r^{\prime}$, the group $C$ at a still slower rate $r^{\prime \prime}$, and so on. Now suppose it arbitrarily agreed that if, for any one of these series, a given change of contents $\Delta$ took place within the span of one of the presented moments of that series, then this degree of change should mean a clear consciousness of the nature of just that change from older to newer conditions, whereas, in so far as contents changed either much less or much more than $\Delta$ during such a presented moment, then these contents and their changes should be relatively obscure for the experience in question, forming only the back- 
ground upon which the clearly apperceived changes stood out. It would then become possible, in one of these series of experiences (whose apperceptive span was so related to the rate $r$ that the required change $\Delta$ took place in the group $A$ during one presentable moment of this series), that the changes of $A$ should stand out clearly, as definite facts, on a dimly apperceived background of the contents $B, C$, and $D$. In a second series, whose contents we may suppose the same as those of the first, but whose apperceptive span has relation to the rate $r^{\prime}$, the changes of $A$ would become obscure, while the changes of $B$ were clear, and so on. Thus what for one of these series of experiences was the clearly apperceived relation of new and old, would be, in another series, represented only by bafflingly swift and confused tremulousness of contents, or by apparently changeless contents. What one experience might indirectly come to regard as a conceivable secular variation of the content which, so far as its own direct apperception went, is found unalterable, another experience, substantially agreeing with the first in all but the apperceptive span, would have presented to itself as definitely changing material. What one experience, therefore, viewed as seemingly unalterable, and consequently unmeaning routine, the other would apperceive as significant and momentary change.

Let one now further suppose, however, that through the addition of still other elements to each of these series of experiences, the presence of one series became communicated to the others by phenomenally observable manifestations. Then surely one can conceive each series of experiences as aware, more or less indirectly, of the presence, and even of the inner reality of its neighbors. But of the meaning of this other life each series could form a directer sort of appreciation only in so far as the apperceptive span of one series agreed with that of another. Socially definite communication could occur only between types of experience of substantially the same apperceptive span. Finally, if one supposes the phenomenally indicated contents of the various series to involve many unlikenesses, as well as many agreements in the different series themselves, one approaches the conception of a system of series of experiences whereof any one series might manifest its presence to its neighbors, while the inner life and meaning of one series could be concretely realized by another only in so far as, along with much agreement in their contents, there was also close agreement in apperceptive span. But if a series of slowly changing contents, and of vast apperceptive span, 
manifested its presence to a series of swiftly changing contents, and of brief apperceptive span, then the only representative of the first series in the life of the second would be a group of changeless, or of rhythmically repeated phenomena, which would seem to manifest no intelligible inner life as such, but only those habits which form, not the whole, but a single aspect of the phenomenal life of any being whose inner experience his neighbor can interpret-only such habits, but no significant variations or adjustments of habits.

If one again reviews, in the light of these considerations, the facts before considered, one finds a situation which our single supplementary hypothesis now enables us in general to understand. This hypothesis is that the apperceptive span of finite experience is a quantity relatively fixed for our social fellows, but very vastly variable in the realm of cosmical experience in general. The "other experience than ours," of which we suppose the inner life of nature to consist, is everywhere an experience of new contents viewed on the background of old contents, of changes arising on a basis of identity, of novelty contrasted with familiarity. In order that such streams of gradual change should be inwardly appreciable, the change must everywhere be present, to a finite degree, within one presented moment of the series of experiences to which, in each case of conscious experience, this appreciation belongs. But a present moment does not mean a mathematical instant. It means, in any type of conscious experience, a period of time equal to the apperceptive span, and this period, in case of any given finite experience, might as well be a world-cycle as a second. Only, in case a type of changing experience whose apperceptive span is a world-cycle, hints its contents to a sort of experience whose apperceptive span is brief, like ours, then the phenomenal manifestation in question may, to any extent, take the form of an apparently final uniformity of contents, such as we seem to observe in the secular uniformities of physical nature. But, where uniformity alone is suggested, the element of change of contents, upon which every appreciation of any inner experience depends, is absent. One then seems to be apperceiving only fixed laws, absolute routine, settled habits of nature, and can detect no inner meanings, unless by the aid of the most fanciful analogies. Between experience of this august span and our human experience a relatively continuous series of types of experience may lie, whose presence gets manifested to us in processes of increasing phenomenal irregularity, such as those of organic nature. Nearest to our own type 
of human experience would doubtless lie masses of "subliminal" experience related to those changing habits of our own organisms which escape our apperceptive span. Below our own brief span there may lie types of experience of still briefer span, whose phenomenal manifestations have, like the hypothetical collisions of the molecules of a gas, an enormous irregularity, such as only the law of averages, as revealed by the doctrine of chances, enables us to conceive of resulting, by virtue of the vast numbers of facts that are concerned, in a secondary regularity of outward seeming when these facts are grouped in great masses.

But in itself, nature, as such, would be neither a world of fixed habits or yet a world of mere novelties, but rather a world of experience with permanence everywhere set off by change. For the rest, the problem which has been raised by Mr. Charles Peirce (to whose brilliant cosmological essays the foregoing discussion, despite the indicated disagreements, obviously owes very much)-the problem whether in nature there is any objective "chance," and whether all natural law is, in the last analysis, a product of evolution, has been in the foregoing, deliberately ignored. It is a problem, as above remarked, whose discussion belongs elsewhere than in this context. 
